\title{
Association of SYT-SSX Fusion Types with Proliferative Activity and Prognosis in Synovial Sarcoma
}

Hiroshi Inagaki, M.D., Tetsuro Nagasaka, M.D., Takanobu Otsuka, M.D., Eiji Sugiura, M.D., Nobuo Nakashima, M.D., Tadaaki Eimoto, M.D.

Departments of Pathology (HI, TE) and Orthopedics (TO), Nagoya City University Medical School, and Departments of Laboratory Medicine (TN, NN) and Orthopedics (ES), Nagoya University Medical School, Nagoya, Japan

The $t(X ; 18)(p 11.2 ; q 11.2)$ translocation commonly found in synovial sarcoma (SS) results in the fusion of the SYT gene on chromosome 18 to either of two closely related genes, SSX1 and SSX2, on chromosome $X$. It has been suggested that patients who have SS bearing SYT-SSX1 fusion have worse prognosis than those bearing SYT-SSX2 fusion. However, little is known about the biologic basis or the relationship with the histopathologic risk factors in regard to the different fusion types. We analyzed 19 cases of SS with no metastasis at diagnosis. These tumors were classified by reverse transcription-polymerase chain reaction to SYT-SSX1 and SYT-SSX2 types. The expression of Ki-67, p27, p53, and bcl-2 and various clinicopathologic parameters including mitotic rate were compared between the two fusion types. The SYT-SSX1 type fusion was associated with high Ki-67 expression $(P=.011)$ and high mitotic rate $(P=.070)$. No significant differences were found between the two types as to the expression of p27, p53, and bcl-2 and other clinicopathologic parameters. The survival analysis showed that SYT-SSX1-type fusion, high Ki-67 expression, and high mitotic rate correlated with shorter metastasis-free survival. These data suggested that SYT-SSX fusion type is associated with tumor cell proliferative activity and prognosis of patients who have SS.

KEY WORDS: Ki-67, Mitotic activity, Proliferation, Reverse transcription-polymerase chain reaction, Survival, Synovial sarcoma, SYT-SSX. Mod Pathol 2000;13(5):482-488

Copyright $\odot 2000$ by The United States and Canadian Academy of Pathology, Inc.

VOL. 13, NO. 5, P. 482, 2000 Printed in the U.S.A.

Date of acceptance: October 26, 1999.

This work was supported by a Grant-in-Aid for Scientific Research from the Ministry of Education, Science, and Culture, Japan (Grant No. 11670185), and by the Grant for Medical Research from Ojinkai, Nagoya. Address reprint requests to: Hiroshi Inagaki, M.D., Department of Pathology, Nagoya City University Medical School, Kawasumi-1, Mizuho-ku, Nagoya 467-860 1, Japan; e-mail: hinagaki@med.nagoya-cu.ac.jp; fax: 8152-851-4166.
Synovial sarcoma (SS) accounts for approximately $10 \%$ of soft tissue sarcomas and occurs mainly in adolescents and young adults (1). A characteristic chromosomal translocation, $\mathrm{t}(\mathrm{X} ; 18)$ (p11.2;q11.2), has been found in most of the cases, and it is suggested that this translocation is the primary causative event of SS $(2,3)$. Cloning of the translocation breakpoints and other molecular studies revealed that the proximal portion of the SYT gene at $18 \mathrm{q} 11$ is fused with the distal portion of one of two duplicated genes at Xp11, SSX1 or SSX2 $(4,5)$. Because the SYT-SSX fusion is found in more than $95 \%$ of the cases (5-7), its detection has been used as a sensitive diagnostic test for SS. Recently, molecular diagnosis using reverse transcription-polymerase chain reaction (RT-PCR) has been successfully performed using RNA extracted not only from frozen materials but also from archival histologic (8-10) or cytologic specimens (10). Five different related SSX gene transcripts, SSX1-5, have been identified (11). The sequences of SSX3, SSX4, and SSX5 transcripts share a high sequence homology with that of SSX2. These SSX genes rarely are involved in the SYT-SSX fusion in SS, and only one SYT-SSX4 case has been reported (12).

Although the function of SYT, SSX, and SYT-SSX genes remains to be elucidated, the type of SYT-SSX fusion transcript may correlate with the clinical behavior of SS; tumors with SYT-SSX1 fusion transcript present worse prognosis than those with SYTSSX2 (7). However, the underlying biology of this observation and its histopathologic implications are poorly elucidated. We previously presented a preliminary study suggesting that SYT-SSX fusion types are associated with the tumor proliferative activity and patients' prognosis (13). Nilsson et al. (14) reported similar findings.

In the present study, we determined by RT-PCR the fusion type (SYT-SSX1 or SYT-SSX2) of the SS and examined its correlation with the immunohistochemical expression of Ki-67, p27, p53, and bcl-2, factors useful in studying tumor cell proliferation, in estimating tumor aggressiveness and for a differ- 
ential diagnosis (15-17). In addition, survival analysis was performed using these four immunohistochemical markers, SYT-SSX fusion types, mitotic rate, and other clinical parameters.

\section{MATERIALS AND METHODS}

\section{Synovial Sarcoma Cases}

Twenty-three primary SS cases were selected from the files of the Departments of Pathology of Nagoya City University Hospital and Nagoya University Hospital. Because 4 patients had distant metastases at diagnosis, the remaining 19 patients who had localized tumors were included in the present study. Partial clinical and molecular data on eight of these patients were described in a previous report (10). All specimens obtained at biopsy were fixed in $10 \%$ buffered formalin and embedded in paraffin. Cytologic specimens stained with Giemsa were also prepared in eight of the cases. The age at diagnosis ranged from 13 to 62 years (average, 31 years). There were 8 male and 11 female patients. All tumors were deep seated; 15 tumors occurred in the extremities, and the other 4 occurred in the central axis. All patients were surgically treated with curative intent, but one patient had a microscopically positive margin. The greatest diameter of the tumor was less than $5 \mathrm{~cm}$ in four cases. Adjuvant chemotherapy was administered to 16 patients. Follow-up data were available from all of the patients. The postoperative follow-up period ranged from 6 to 108 months (average, 36 months). Eleven cases developed metastases, and the recurrent tumors were surgically treated when they were localized in one organ. Seven patients died of disease, 2 were alive with disease, and 10 showed no evidence of disease.

\section{Reverse Transcription-Polymerase Chain Reaction}

Total RNA extracted from the paraffin and/or cytologic materials was subjected to one tube RTPCR followed by a nested PCR, as described previously (10). Briefly, extracted RNA was heated at $70^{\circ}$ $\mathrm{C}$ and placed on ice. Then, RT-PCR mixture was added and the final mixture was as follows: 8.25 units of RNase inhibitor (Toyobo, Osaka, Japan), 50 units of Moloney murine leukemia virus reverse transcriptase (Gibco BRL, Rockville, MD), 25 pm of each outer primer (P1, CACAGGGACAAGGTCAGC, and P2, TTGTGGGCCAGATGCTTC), $200 \mu \mathrm{m}$ of each of the four deoxynucleotides, 1 unit of Taq GOLD DNA polymerase (Applied Biosystems, Foster City, CA), and $1 \times$ Taq buffer containing $1.5 \mathrm{~mm} \mathrm{MgCl}_{2}$. The thermocycler was programmed first to incubate the samples for $50 \mathrm{~min}$ at $37^{\circ} \mathrm{C}$ for the initial
RT step; next for $10 \mathrm{~min}$ at $95^{\circ} \mathrm{C}$ for inactivation of the reverse transcriptase as well as for activation of the DNA polymerase; and then to carry out $30 \mathrm{cy}-$ cles of PCR consisting of $95^{\circ} \mathrm{C}$ for 30 seconds, $50^{\circ} \mathrm{C}$ for 30 seconds, and $72^{\circ} \mathrm{C}$ for 30 seconds. The firstround PCR product was further amplified in the nested PCR with the forward primer, P3 (AGCCTGGACCACCACAGC) for SYT, and one of the following reverse primers: $\mathrm{P} 4$ (consensus, CCTCTGCTGGCTTCTTGG) for SSX, P5 (TGCTTCTGACACTCCCTT) for SSX1, and P6 (TGCTTCTGGCACTTCCTC) for SSX2. The amplification conditions consisted of 30 cycles of $95^{\circ} \mathrm{C}$ for 30 seconds and $60^{\circ} \mathrm{C}$ for 30 seconds. We identified the final PCR products on the basis of size on $10 \%$ polyacrylamide gels and confirmed the results in all cases by restriction enzyme digestion with Sau3AI and HaeIII (10) or if necessary by a direct sequencing with the dideoxy chain-termination method modified for fluorescent- based DNA sequencer (model 310; Applied Biosystems). Used as positive controls were frozen materials obtained from SS cases bearing SYT-SSX1 or SYT-SSX2 fusion products, which had been confirmed by direct sequencing. A variety of unrelated lesions were used as negative controls. All samples were tested in at least two separate experiments. Monitoring controls included reactions lacking RNA and reactions lacking reverse transcriptase.

\section{Immunohistochemistry}

Sections were immunostained for Ki-67, p27, p53, and bcl-2 using the streptavidin-biotin method. Deparaffinized sections were treated with $0.3 \%$ hydrogen peroxide for 30 min to block endogenous peroxidase. To unmask the epitope, high-temperature treatment of the sections was performed (microwave treatment for bcl-2 and pressure cooker treatment for Ki-67, p27, and p53). Sections were incubated with the primary monoclonal antibody: antiKi-67 (MIB-1; Immunotech, Marseilles, France), anti-p27 (57; Transduction Lab, Lexington, KY), anti-p53 (DO-7; DAKO, Kyoto, Japan), and antibcl-2 (124, DAKO). The signals were detected using HistoFine streptavidin-biotin kit (Nichirei, Tokyo, Japan), which resulted in brown color. For negative controls, the primary antibody was omitted. A known positive control for each antibody was also used to check proper staining.

To assess the ratio of positive nuclei for Ki-67 and p27, each slide was studied under high-power magnification $(\times 400)$, and the tumor cells showing distinct nuclear reaction product were counted regardless of intensity, using a computer-assisted image-analyzing system (VM-30; Olympus, Tokyo, Japan). Cells of the tumor vascular component and hematogenous cells were excluded from the analy- 
sis. We evaluated a standardized number of 1000 neoplastic cells from multiple representative fields. The ratio of positive nuclei to the total number of tumor cells was expressed as a labeling index (LI). Positivity for p53 and bcl-2 was evaluated as follows: a tumor with greater than $5 \%$ distinctly positive neoplastic cells was considered positive, and a tumor with fewer than 5\% immunoreactive cells was considered negative.

\section{Statistics}

The unpaired $t$ test or Fischer's exact test determined the statistical significance between parameters. Parameters expressed by the metric scale (Ki-67 LI and p27 LI) were analyzed with the unpaired $t$ test. The correlation between the Ki-67 LI and the p27 LI was calculated with the simple regression analysis. The probability of overall or disease-free survival was computed according to the Kaplan-Meier method. The day of the primary surgery was considered as the start of the follow-up. Statistical comparison between the curves was based on the log-rank test. All $P$ values were two sided. A $P$ value of less than 0.05 was considered significant, and a $P$ value of less than 0.1 and more than 0.05 was considered marginally significant. All analyses were performed using statistical package StatView version 4.5.1 (Abacus Concepts, Inc., Berkeley, CA).

\section{RESULTS}

\section{Tumor Histology, RT-PCR, and Typing of}

\section{SYT-SSX Fusion}

Review of the hematoxylin and eosin-stained sections of the tumor specimens showed that all tumors had histologic features consistent with SS. The tumors were histologically subclassified as either biphasic (6 cases; Fig. 1A) or monophasic (13 cases; Fig. 1B) type. Positive staining for cytokeratin and/or epithelial membrane antigen further supported the diagnosis, especially in monophasic fibrous type. Osseous metaplasia and extensive necrosis were found in one and two cases, respectively. The mitotic rate was determined by counting the number of mitoses in 10 high power $(\times 400)$ fields $(\mathrm{HPF})$. The patients were divided into those who had fewer than 15 mitoses per $10 \mathrm{HPF}$ and those who had more than 15 mitoses per $10 \mathrm{HPF}$ according to the published convention $(1,18)$. High mitotic rate was shown in nine tumors (Fig. 1B). The RT-PCR analysis using histologic specimens as an RNA source showed that all cases had chimeric SYT-SSX transcript (Fig. 2A). The result was confirmed by restriction enzyme digestion or direct sequencing.
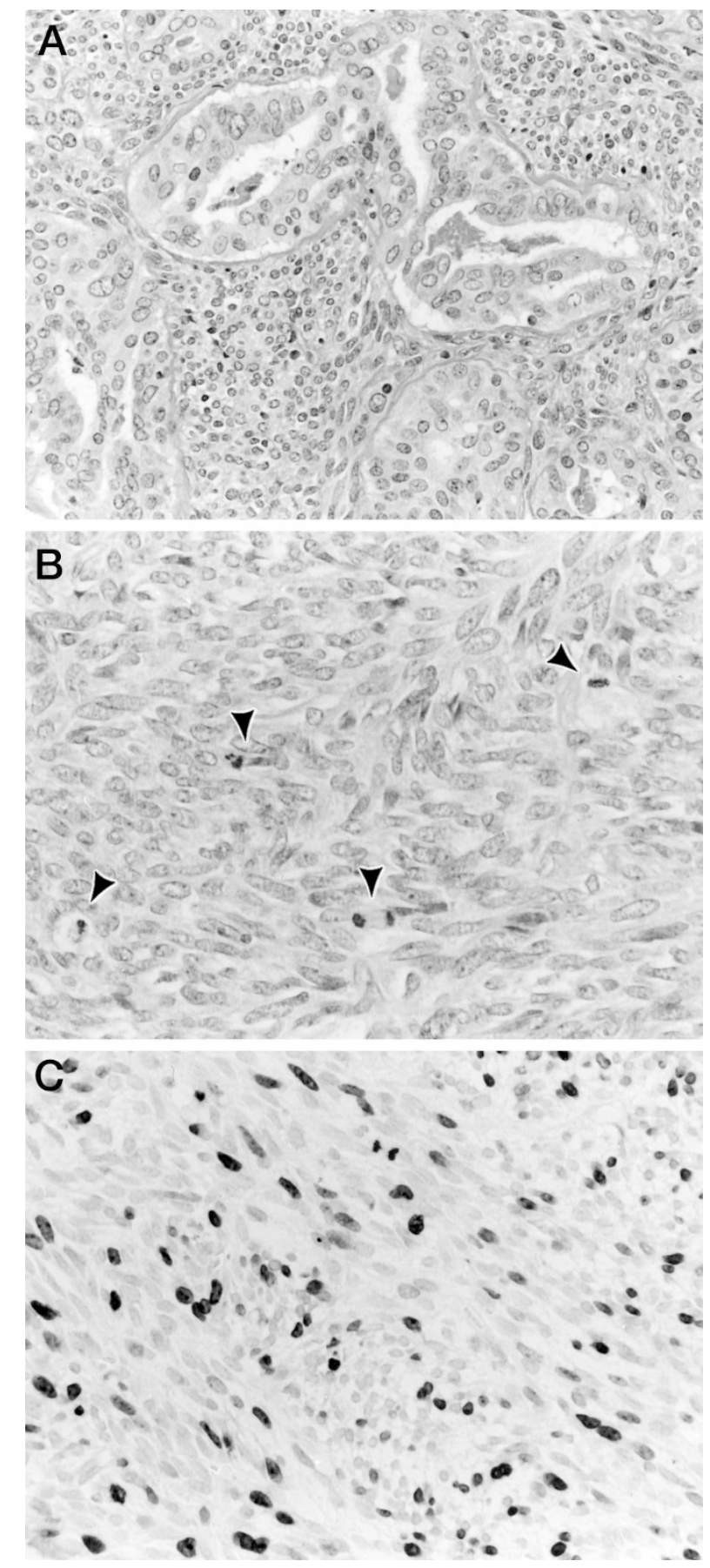

FIGURE 1. A, synovial sarcoma of biphasic type (hematoxylin and eosin stain; original magnification, $\times 80$ ). B, synovial sarcoma of monophasic type showing many mitotic figures (arrowheads) (hematoxylin and eosin stain; original magnification, $\times 100$ ). C, distinct nuclear staining of Ki-67 antigen is detected in many tumor cells, monophasic type (original magnification, $\times 100$ ).

None of the cases showed atypical transcript such as an insertion and a deletion. The nested PCR using a primer specific to either SSX1 or SSX2 gene revealed that there were 10 tumors expressing SYT-SSX1 transcript and 9 expressing SYTSSX2 transcript (Fig. 2B, C). The RT-PCR using cytologic specimens as an RNA source showed an identical result. 

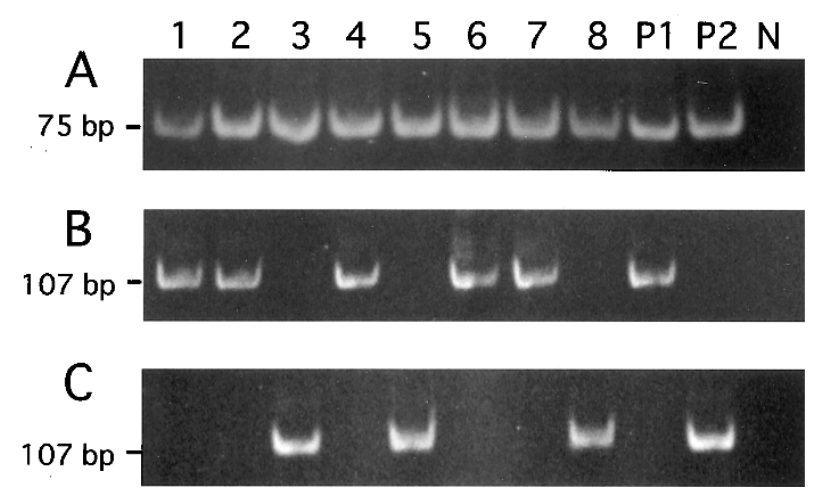

FIGURE 2. Identification of SYT-SSX (A), SYT-SSX1 (B), and SYT-SSX2 (C) fusion transcripts in synovial sarcoma by reverse transcription-polymerase chain reaction. The size of the consensus SYT-SSX product is $75 \mathrm{bp}$, and the SYT-SSX1 and SYT-SSX2 products both are $107 \mathrm{bp}$. Lanes 1-8, synovial sarcomas with SYT-SSX1 fusion (Lanes 1, 2, 4, 6, and 7) and SYT-SSX2 fusion (Lanes 3, 5, and 8); P1, positive control showing SYT-SSX1 fusion; P2, positive control showing SYT-SSX2 fusion; N, negative control.

\section{Correlation of SYT-SSX Fusion Types with Clinicopathologic Factors}

The correlation of SYT-SSX fusion types with various parameters analyzed is summarized in Table 1. Ki-67 LI was $20.6 \%$ in tumors bearing SYT-SSX1 type fusion, compared with $5.2 \%$ in those with SYTSSX2, showing that the former tumors were more proliferative than the latter $(P=.011$; Fig. $1 C)$. The SYT-SSX1-type tumors showed somewhat higher p27 LI than the SYT-SSX2-type tumors, but the statistical significance was not obtained. When the

TABLE 1. Correlation Between Fusion Types (SYT-SSX1 or SYT-SSX2) and Various Clinicopathologic Parameters

\begin{tabular}{|c|c|c|c|}
\hline Variables & SSX1 & SSX2 & $P$ \\
\hline Ki-67 LI ${ }^{a}(\%)$ & $20.6 \pm 4.9$ & $5.2 \pm 1.6$ & 0.011 \\
\hline p27 LI (\%) & $30.8 \pm 9.4$ & $18.2 \pm 5.0$ & NS \\
\hline \multicolumn{4}{|l|}{ p53 (cases) } \\
\hline Positive & 5 & 3 & \\
\hline Negative & 5 & 6 & NS \\
\hline \multicolumn{4}{|l|}{ bc1-2 (cases) } \\
\hline Positive & 9 & 6 & \\
\hline Negative & 1 & 3 & NS \\
\hline \multicolumn{4}{|c|}{ Histologic subtype (cases) } \\
\hline Biphasic & 4 & 2 & \\
\hline Monophasic & 6 & 7 & NS \\
\hline \multicolumn{4}{|l|}{ Mitotic rate ra $^{a}$} \\
\hline$>15 / 10 \mathrm{HPF}$ & 7 & 2 & \\
\hline$<15 / 10 \mathrm{HPF}$ & 3 & 7 & 0.070 \\
\hline \multicolumn{4}{|l|}{ Age $(y)$} \\
\hline$<15$ & 3 & 2 & \\
\hline$>15$ & 7 & 7 & NS \\
\hline \multicolumn{4}{|l|}{ Sex (cases) } \\
\hline Male & 6 & 2 & \\
\hline Female & 4 & 7 & NS \\
\hline \multicolumn{4}{|l|}{ Location (cases) } \\
\hline Extremities & 8 & 7 & \\
\hline Central axis & 2 & 2 & NS \\
\hline \multicolumn{4}{|l|}{ Size (cases) } \\
\hline$<5 \mathrm{~cm}$ & 2 & 1 & \\
\hline$>5 \mathrm{~cm}$ & 8 & 8 & NS \\
\hline
\end{tabular}

HPF, high-power $(\times 400)$ fields; NS, not significant.

${ }^{a}$ Mitotic rate is correlated with Ki-67 LI $(P=.003)$. correlation between Ki-67 LI and p27 LI was studied by a regression analysis, there was only a little association between the two (p27 LI $=20.2+0.35 \times$ Ki-67 LI, $\mathrm{R}^{2}=0.039$ ). p53 protein was positive in 8 of 19 cases $(42 \%)$ and often detected in the tumor element showing epithelial differentiation, although p53 was not significantly related to the SYTSSX types. bcl-2 protein was frequently positive (15 of 19 cases, $79 \%$ ) but not correlated with the SYTSSX types. The SYT-SSX1 type was associated with high mitotic rate with a marginal significance $(P=$ .070). Other histologic or clinical factors (histologic subtypes, sex, age, tumor site, and tumor size) did not show any significant correlation with the SYTSSX types.

\section{Survival Analysis}

Factors included in the survival analysis were as follows: SYT-SSX type, Ki-67, p27, p53, bcl-2, histologic subtype, age, sex, site, size, and chemotherapy. The extensive necrosis and osseous metaplasia were not included as parameters because the number of the cases showing such changes was small. With respect to the parameters expressed by the metric scale (Ki-67 LI and p27 LI), tumors were divided into two groups for the survival analysis after producing the scatter plots. The cutoff value for Ki-67 LI and p27 LI was 15\% and 10\%, respectively. There were six cases of high Ki-67 expressors and five of high p27 expressors.

In the overall survival analysis, 5-year survival rate was $56 \%$. No parameters analyzed achieved the statistical significance in predicting the prognosis. When metastasis-free survival was analyzed, the 5 -year survival rate was $47 \%$. The patients with SYT-SSX1 tumor showed a worse metastasis-free survival than those with SYT-SSX2 with a marginal significance $(P=.078$; Fig. $3 \mathrm{~A})$. The survival was significantly shorter in SS patients with high Ki-67 expression $(P=.010$; Fig $3 \mathrm{~B})$ and in those with high mitotic rate ( $P=.002$; Fig. $3 C)$. p27, p53, and bcl-2 were not useful in predicting the survival. None of the other histologic or clinical factors significantly influenced the metastasis-free survival rate. When the association between three selected risk factors was analyzed, a close correlation was found with each other (SYT-SSX1 type versus high Ki-67 LI, $P=$ .011; SYT-SSX1 versus high mitotic rate, $P=.070$; high Ki-67 LI versus high mitotic rate, $P=.003$ ).

\section{DISCUSSION}

In some malignant soft tissue tumors, the type of fusion created by chromosomal translocation has been shown to be prognostically relevant. Patients who have Ewing's sarcomas showing the EWS-FLI1 type 1 (EWS exon 7 joined in frame with exon 6 of 

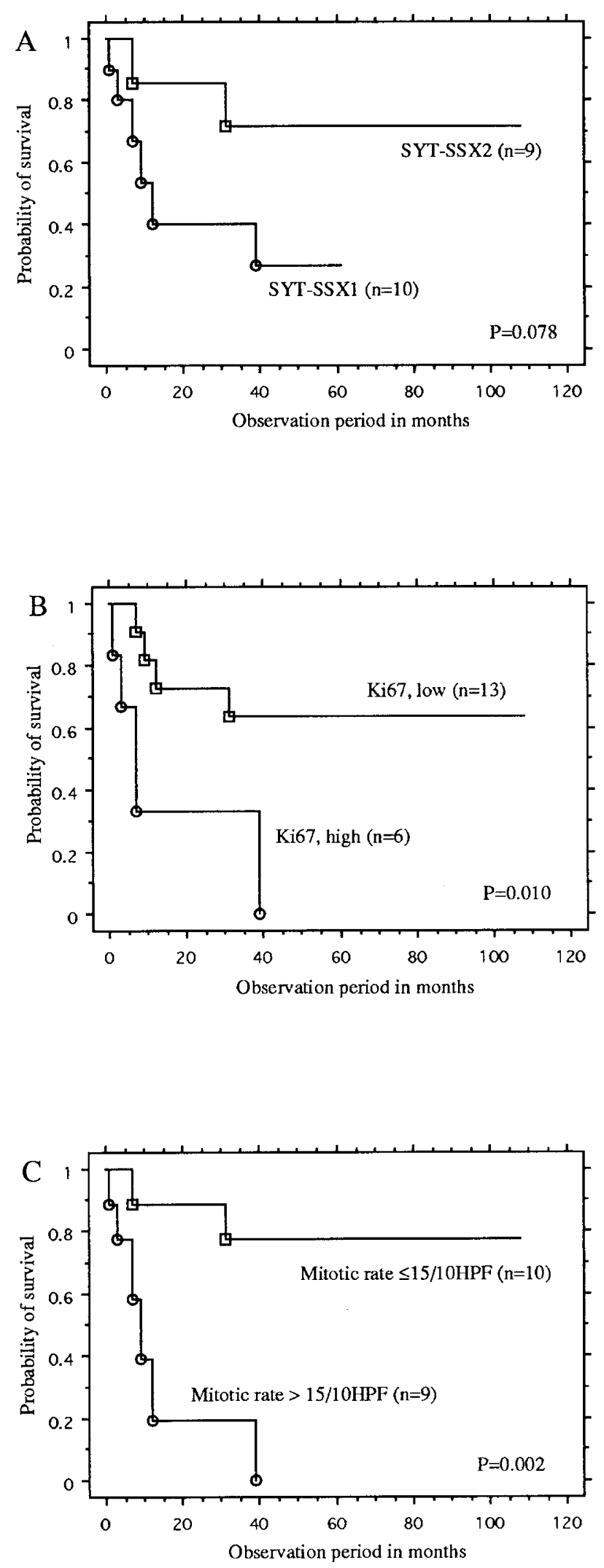

FIGURE 3. Metastasis-free survival of 19 patients with synovial sarcoma analyzed for SYT-SSX fusion types (A), Ki-67 expression (B), and mitotic rate $(\mathbf{C})$.
FLI1) had a better prognosis than those showing other types of fusion transcript (19). In rhabdomyosarcoma, PAX7-FKHR-type fusion transcript was a novel marker for a better prognosis (20). A similar observation has been recently reported in SS that the type of SYT-SSX fusion transcript correlated with the clinical behavior of the tumors; patients who had SYT-SSX1 tumors had worse prognosis than patients who had SYT-SSX2 tumors (7). However, the underlying biology or the relationship of the fusion types with histologic or clinical risk factors is not clear.

In the present study, 19 primary tumors confirmed as SS by RT-PCR were molecularly classified as those bearing SYT-SSX1-type fusion or those bearing SYT-SSX2. The proportion of SYT-SSX fusion types paralleled that found in the literature (5-7). Expression of Ki-67, p27, p53, and bcl-2 was immunohistochemically examined and compared with the type of SYT-SSX fusion. Tumors with SYTSSX1-type fusion had a significantly higher Ki-67 LI than those with SYT-SSX2. None of other immunohistochemical parameters analyzed was associated significantly with the types of SYT-SSX fusion. In the survival analysis, SYT-SSX1-type fusion, high Ki-67 LI, and increased mitotic activity were selected as prognostic factors for shorter metastasisfree survival. Further analysis showed that these three factors were associated with each other. The $\mathrm{Ki}-67$ antigen is a DNA-binding nuclear protein of 395 and $345 \mathrm{kDa}$, which is expressed in the proliferating cells (G1, S, G2, and M phases) but undetectable in the resting cells (21). Although the number of cases studied was limited, our findings suggest that the type of SYT-SSX fusion is associated with the proliferation of the tumor cells and clinical aggressiveness of the SS. These findings are concordant with the results reported by Nilsson et al. (14).

The function of chimeric SYT-SSX fusion protein is unclear. However, the molecular characterization of the chimeric gene suggests that it is a novel transcriptional coactivator of a sequence-specific DNA-binding protein $(5,22,23)$. The SYT protein, possessing no obvious DNA-binding domain, is rich in proline, glutamine, and glycine, resembling the domains of a number of transcriptional coactivators. A recent observation showed that the SYT protein has transcriptional activation properties (22). The SSX proteins also have no recognizable DNAbinding domain but have a Kruppel-associated box transcriptional repressor domain in the $N$-terminal region and a probable protein-binding domain in the C-terminal region (5). When SYT and SSX genes are fused, the SYT-SSX protein is subsequently composed of the transcriptional activation domain of the SYT protein and the protein-binding domain of the SSX protein. The former SYT domain might 
activate the normally repressed target proteins by the SSX proteins, which is considered to be the primary causal event in SS. Our finding that the SYT-SSX fusion types are associated with the tumor cell proliferation as determined by Ki-67 LI and mitotic rate may give further evidence that the SYTSSX protein is a transcriptional regulator. However, the precise molecular mechanism of how the types of SYT-SSX fusion transcript influence the clinical aggressiveness of SS is still not clear. Our speculation is that the differences in amino acids of the protein-binding domain of the SYT-SSX proteins may affect specific protein-protein interactions, altering the target gene specificity of SYT-SSX chimeric proteins or the degree of transactivation of target gene subgroups, and finally influence the tumor cell proliferation and thus the clinical aggressiveness of the SS.

p27, a member of the cyclin-dependent kinase inhibitor family, is regulated by cell contact inhibition and by transforming growth factor- $\beta$ (24). In epithelial and lymphoid tumors, p27 expression is inversely related to Ki-67 expression, and low p27 expression was characterized as an independent prognostic marker in many tumors, including those of the breast, colon, and prostate (25). However, the significance of p27 in soft tissue neoplasms has not been determined. In our study, p27 expression did not correlate with Ki-67 expression or have a prognostic value in SS. Similar observations were reported in several endocrine tumors (26), and some genetic defects might allow these neoplasms to proliferate despite high p27 expression. The implication of p27 expression in sarcomas should further be elucidated.

A correlation between the histologic subtype and the SYT-SSX type has been suggested; biphasic tumors were associated with SYT-SSX1 rearrangement, and monophasic tumors were associated predominantly, but not exclusively, with SYT-SSX2 rearrangement $(7,27)$. However, this relationship has been controversial even in the studies using a large series of samples $(5,9)$ and was not shown in the present SS cases. Sampling bias and subtyping criteria may partly account for this discrepancy.

Various prognostic factors for SS have been reported (e.g., histologic subtype, mitotic activity, extensive necrosis, osseous metaplasia, age, site, size, and most recently SYT-SSX fusion types [1, 7, 9]). However, these factors did not always emerge as prognostic factors in the recent studies in which diagnosis of SS was established by RT-PCR $(7,9)$. In the present study, the mitotic activity, SYT-SSX fusion types, and Ki-67 expression emerged as prognostic factors. The discrepancy as to the prognostic factors between previous and recent studies may be partly explained by the recent advances in SS treatments as well as the establishment of the SS diag- nosis by molecular techniques. Multivariate studies with a larger number of patients and a longer follow-up are needed to determine the risk factors for SS.

Acknowledgments: We thank E. Tochizawa and C. Ando for their invaluable technical assistance.

\section{REFERENCES}

1. Enzinger FM, Weiss SW. Synovial sarcoma. In: Enzinger FM, Weiss SW, editors. Soft tissue tumors. 3rd ed. St. Louis: Mosby; 1995. p. 757-86.

2. Ladanyi M. The emerging molecular genetics of sarcoma translocation. Diagn Mol Pathol 1995;4:162-73.

3. Sorensen PHB, Triche TJ. Gene fusions encoding chimeric transcription factors in solid tumors. Semin Cancer Biol 1996;7:3-14.

4. Clark J, Rocques PJ, Crew AJ, Gill S, Shipley J, Chan AML, et al. Identification of novel genes, SYT and SSX, involved in the $\mathrm{t}(\mathrm{X} ; 18)(\mathrm{p} 11.2 ; \mathrm{q} 11.2)$ translocation found in human synovial sarcoma. Nat Genet 1994;7:502-8.

5. Crew AJ, Clark J, Fisher C, Gill S, Grimer R, Chand A, et al. Fusion of SYT to two genes, SSX1 and SSX2, encoding proteins with homology to the Kruppel-associated box in human synovial sarcoma. EMBO J 1995;14:2333-40.

6. Fligman J, Lonardo F, Jhanwar SC, Gerad WL, Woodruff J, Ladanyi M. Molecular diagnosis of synovial sarcoma and characterization of a variant SYT-SSX2 fusion transcript. Am J Pathol 1995;147:1592-9.

7. Kawai A, Woodruff J, Healey JH, Brennean MF, Antonescu CR, Ladanyi M. SYT-SSX gene fusion as a determinant of morphology and prognosis in synovial sarcoma. N Engl J Med 1998;338:153-60.

8. Argani P, Zakowski MF, Klimstra DS, Rosai J, Ladanyi M. Detection of the SYT-SSX chimeric RNA of synovial sarcoma in paraffin-embedded tissue and its application in problematic cases. Mod Pathol 1998;11:65-71.

9. Tsuji S, Hisaoka M, Morimitsu Y, Hashimoto H, Shimajiri S, Komiya S, et al. Detection of SYT-SSX fusion transcripts in synovial sarcoma by reverse transcription-polymerase chain reaction using archival paraffin-embedded tissues. Am J Pathol 1998;153:1807-12.

10. Inagaki $H$, Murase $T$, Otsuka $T$, Eimoto $T$. Detection of SYT-SSX fusion transcript in synovial sarcoma using archival cytologic specimens. Am J Clin Pathol 1999;111:528-33.

11. Gure AO, Tureci O, Sahin U, Tsang S, Scanlan MJ, Jager E, et al. SSX: a multigene family with several members transcribed in normal testis and with human cancer. Int J Cancer 1997;72:965-71.

12. Skytting B, Nilsson G, Brodin B, Xie Y, Lundeberg J, Uhlen M, et al. A novel fusion gene, SYT-SSX4, in synovial sarcoma [letter]. J Natl Cancer Inst 1999;91:974-5.

13. Inagaki H, Murase T, Shimokawa K, Eimoto T. Expression of MIB-1 antigen and P-glycoprotein in synovial sarcoma [abstract]. Proc Jpn Soc Pathol 1999;88:280 (in Japanese).

14. Nilsson G, Skytting B, Xie Y, Brodin B, Perfekt R, Mandahl N, et al. The SYT-SSX1 variant of synovial sarcoma is associated with a high rate of tumor cell proliferation and poor clinical outcome. Cancer Res 1999;59:3180-4.

15. Lopes JM, Hannisdal E, Bjerkehagen B, Bruland OS, Danielsen HE, Pettersen EO, et al. Synovial sarcoma. Evaluation of prognosis with emphasis on the study of DNA ploidy and proliferation (PCNA and Ki-67) markers. Anal Cell Pathol 1998;16:45-62.

16. Taubert H, Meye A, Wurl P. Prognosis is correlated with p53 mutation type for soft tissue sarcoma patients. Cancer Res 
1996;56:4134-6.

17. Suster S, Fisher C, Moran CA. Expression of bcl-2 oncoprotein in benign and malignant spindle tumors of soft tissue, skin, serosal surfaces, and gastrointestinal tract. Am J Surg Pathol 1998;22:863-72.

18. Oda Y, Hashimoto H, Tsuneyoshi M, Takeshita S. Survival in synovial sarcoma. A multivariate study of prognostic factors with special emphasis on the comparison between death and long-term survival. Am J Surg Pathol 1993;17:35-44.

19. de Alava E, Kawal A, Healey JH, Fligman I, Meyers PA, Juvos AG, et al. EWS-FLI1 fusion transcript structure is an independent determinant of prognosis in Ewing's sarcoma. J Clin Oncol 1998;16:1248-55.

20. Kelly KM, Womer RB, Sorensen PHB, Xiong QB, Barr FG. Common and variant gene fusions predict distinct clinical phenotypes in rhabdomyosarcoma. J Clin Oncol 1997;15: 1831-6.

21. Gerdes J, Li L, Schlueter C, Duchrow M, Wohlenberg C, Gerlach C, et al. Immunobiochemical and molecular biologic characterization of the cell proliferation-associated nuclear antigen that is defined by monoclonal antibody Ki-67. Am J Pathol 1991;138:867-73.
22. Brett D, Whitehouse S, Antonson P, Shipley J, Cooper C, Goodwin $G$. The SYT protein involved in the $t(X ; 18)$ synovial sarcoma translocation is a transcriptional activator localised in nuclear bodies. Hum Mol Genet 1997;6:1559-64.

23. Thaete C, Brett D, Monaghan P, Whitehouse S. Functional domains of the SYT and SYT-SSX synovial sarcoma translocation proteins and co-localization with the SNF protein BRM in the nucleus. Hum Mol Genet 1999;8:585-91.

24. Polyak K, Kato JY, Solomom MJ, Sherr CJ, Massague J, Roberts JM, et al. p27 Kip1, a cyclin-Cdk inhibitor links transforming growth factor-beta and contact inhibition to cell arrest. Genes Dev 1994;8:9-22.

25. Steeg PS, Abram JS. Cancer prognostics: post, present and p27. Nat Med 1997;3:152-4.

26. Lloyd RV, Erickson LA, Jin L, Kulig E, Qian X, Cheville JC, et al. p27/Kip1. A multifunctional cyclin-dependent kinase inhibitor with prognostic significance in human cancers. Am J Pathol 1999:154:313-23.

27. Shipley J, Crew J, Birdsall S, Gill S, Clark J, Fisher C, et al. Interphase fluorescence in situ hybridization and reverse transcription polymerase chain reaction as a diagnostic aid for synovial sarcoma. Am J Pathol 1996;148:559-67.

\section{Book Review}

\section{Manni A: Endocrinology of Breast Cancer, 400 pp, Totowa, NJ, Humana Press, 1999 (\$125).}

A more appropriate title for this book might be Endocrinology of the Breast in Health and Disease. The focus of this multiauthored text is a state-of-the-art review of the role of hormones in normal breast development and in benign and malignant diseases. The usefulness of this information to anatomic pathology is remote, and, as suggested by the publishers, the expected readership is endocrinologists, oncologists, pharmacologists, and surgeons.

As one might expect, estrogen, progesterone, prolactin, and androgens are the focus of this 400-page, 23-chapter book. The physiologic function and mechanism of action of these hormones and their role in breast cancer development and progression and their use as targets in anticancer therapy are discussed in length and sometimes repeatedly in multiple chapters. Excellent reviews of oncogenes, tumor suppressor genes, growth factors, and tumor stroma in breast cancer are presented in several chapters; however, they seem somewhat out of place in this book.

Physiology, basic research, current advances, molecular biology, and clinical therapies are the focus of this text. Histopathology of breast diseases is presented in only one short, well-written chapter in which entities are discussed and illustrated in their relationship to breast cancer risk. Several chapters contain a significant number of obvious typographical errors. The references are extensive but already dated, as is some of the text.

If you are very interested in the endocrinology of breast development and disease, there probably is no other book available that deals with this area as completely and as currently as this one. Thus, it is a significant contribution to the breast literature.

\section{Susan Fineberg \\ Montefiore Medical Center \\ Bronx, New York}

